Check for updates

Cite this: Phys. Chem. Chem. Phys., 2018, 20, 28319

\section{Structural characterization of nucleotide 5 '-triphosphates by infrared ion spectroscopy and theoretical studies $\dagger$}

\author{
Rianne E. van Outersterp, (D) Jonathan Martens, (D) ${ }^{a}$ Giel Berden, (D) ${ }^{a}$ \\ Jeffrey D. Steill, ${ }^{a}$ Jos Oomens (D) ${ }^{\text {ab }}$ and Anouk M. Rijs (D)*a
}

\begin{abstract}
The molecular family of nucleotide triphosphates (NTPs), with adenosine $5^{\prime}$-triphosphate (ATP) as its best-known member, is of high biochemical importance as their phosphodiester bonds form Nature's main means to store and transport energy. Here, gas-phase IR spectroscopic studies and supporting theoretical studies have been performed on adenosine $5^{\prime}$-triphosphate, cytosine $5^{\prime}$-triphosphate and guanosine $5^{\prime}$-triphosphate to elucidate the intrinsic structural properties of NTPs, focusing on the influence of the nucleobase and the extent of deprotonation. Mass spectrometric studies involving collision induced dissociation showed similar fragmentation channels for the three studied NTPs within a selected charge state. The doubly charged anions exhibit fragmentation similar to the energy-releasing hydrolysis reaction in nature, while the singly charged anions show different dominant fragmentation channels, suggesting that the charge state plays a significant role in the favorability of the hydrolysis reaction. A combination of infrared ion spectroscopy and quantum-chemical computations indicates that the singly charged anions of all NTPs are preferentially deprotonated at their $\beta$-phosphates, while the doubly-charged anions are dominantly $\alpha \beta$-deprotonated. The assigned three-dimensional structure differs for ATP and CTP on the one hand and GTP on the other, in the sense that ATP and CTP show no interaction between nucleobase and phosphate tail, while in GTP they are hydrogen bonded. This can be rationalized by considering the structure and geometry of the NTPs where the final three dimensional structure depends on a subtle balance between hydrogen bond strength, flexibility and steric hindrance.
\end{abstract}

Received 24th May 2018, Accepted 24th October 2018

DOI: $10.1039 / \mathrm{c} 8 \mathrm{cp} 03314 \mathrm{e}$

rsc.li/pccp

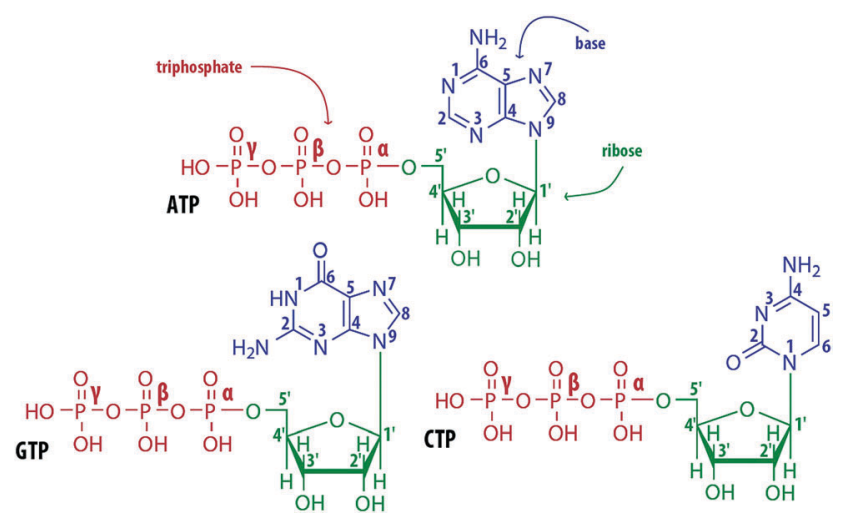

Fig. 1 Chemical structures of fully protonated ATP, CTP and GTP. The colours indicate the base (blue), ribose (green) and triphosphate (red) groups. The standard labelling for triphosphate groups and nucleotide atoms is shown.

phosphate groups, see Fig. 1. The most commonly occurring energy-releasing reaction in nature is the hydrolysis reaction in which the $\beta \gamma$-bond breaks, yielding a phosphate $\left(\mathrm{P}_{\mathrm{i}}\right)$ and 
adenosine $5^{\prime}$-diphosphate (ADP). Cells use the energy released during this reaction to drive their activities by the proteinmediated coupling of this reaction to reactions that require energy. $^{7}$

Since the function and recognition of a biomolecule are tightly related to its three-dimensional structure, detailed insight into the structure of the family of NTPs expedites a full biological understanding. NTPs can be deprotonated at their $\alpha-, \beta$ - and $\gamma$-phosphates and several are indeed deprotonated at physiological $\mathrm{pH}$. The resulting negative charge is stabilized by hydrogen bonds, which largely cement the molecule's threedimensional structure. ${ }^{8}$ In addition, under biological conditions, NTPs are complexed to water molecules, amino acid residues, and metal cations, which stabilize the negative charges on the phosphate groups in solution and catalyse reactions involving NTPs. $^{9-12}$

In the solid phase, $\mathrm{X}$-ray diffraction data is available for some ATP salts, ${ }^{13-18}$ which show a characteristic folding of the phosphate chain towards the nucleobase. The phosphate chain chelates the metal cations and interactions of the nucleobase nitrogen atoms with the cation are rare. The ribose ring commonly adopts a $\mathrm{C}\left(2^{\prime}\right)$ - or $\mathrm{C}\left(3^{\prime}\right)$-endo conformation and the adenine group is in the anti-conformation. The crystals have a doubly charged phosphate chain and a protonated nucleobase, which differs from biological situations. Moreover, it was not possible to crystallize complexes involving divalent cations because of the instability towards hydrolysis. However, it was possible to determine the structure of proteins that bind NTPs as ligands. ${ }^{19}$ Surveys of either ATP/GTP binding sites ${ }^{20}$ or protein structures containing Mg:nucleotide complexes ${ }^{21}$ from the Protein Data Bank ${ }^{22}$ show that the nucleotide has an extended conformation in most cases, so that there is little interaction between the nucleotide and $\beta$ - and $\gamma$-phosphate. Additionally, almost all proteins bind the NTPs in the anticonformation. ${ }^{19}$

In solution, nuclear magnetic resonance (NMR) studies have shown that NTPs, just as in the solid phase, occur predominantly with their base in the anti-conformation. ${ }^{12,23,24}$ Moreover, several studies addressed the acid-base properties of NTP's in aqueous solutions, evidencing that the phosphate-tail is predominantly in its fully deprotonated form. Decreasing the $\mathrm{pH}$ of the solution results firstly in protonation of the $\gamma$-phosphate, secondly in protonation of the nucleobase and finally in protonation of the rest of the phosphate tail. ${ }^{8,25-27}$ Protonation of the nucleobase occurs at N1 of ATP, N7 of GTP and N3 of CTP (see Fig. 1).

Structural studies of biomolecules in the gas-phase add valuable information to condensed-phase studies, since they offer the opportunity to reveal the intrinsic properties of a molecule isolated from the influence of interactions with other molecules or water. Especially the combination of gas-phase infrared spectroscopy and quantum-chemical calculations has been very successful in determining the structure of many biomolecular systems. ${ }^{28}$

Several experimental and theoretical studies have focussed on ATP in the gas phase. ${ }^{29-34}$ Akola and Jones performed a density functional theory (DFT) study of ATP complexes with water and magnesium anions and determined the theoretical structures of isolated ATP and GTP. These structures have the base in the anti-conformation (to reproduce the condensed-phase structure), but the authors suggest that the syn-conformation may be more stable in the gas phase due to interaction between the nucleobase and the phosphate tail. Moreover, their calculations suggest that the phosphate tail is insensitive to the nature of the nucleobase and the ribose group. ${ }^{29}$ Burke et al. performed collision induced dissociation (CID) mass spectrometry and theoretical studies on singly and doubly deprotonated ATP. They observed that CID of doubly deprotonated ATP $\left([\mathrm{ATP}-2 \mathrm{H}]^{2-}\right)$ in the gas phase leads to a hydrolysis-like fragmentation to phosphate and ADP, while CID of singly deprotonated ATP mainly leads to the $\left[\mathrm{H}_{3} \mathrm{PO}_{4}\right]^{1-}$ ion. The calculations provide evidence for $\alpha \beta$-deprotonated [ATP- $2 \mathrm{H}]^{2-}$ and $\alpha$-deprotonated $[\text { ATP-H }]^{1-} \cdot{ }^{30}$ Schinle et al. performed a combined computational and IR spectroscopic study on doubly deprotonated ADP and ATP and provided additional evidence that the ATP dianion is deprotonated on the $\alpha$ - and $\beta$-phosphate. ${ }^{31}$ Both studies suggest that the charges on the phosphate tail are stabilized by intramolecular hydrogen bonds. Complexation of gasphase ATP with metal cations has been addressed by various researchers, showing that complex formation lowers the activation barrier to hydrolysis and stabilizes the excess charge. ${ }^{32,33}$ Cercola et al. recently recorded UV photo-dissociation spectra and fragmentation data for the anions of ATP, ADP and AMP (adenosine $5^{\prime}$-monophosphate). ${ }^{34}$ DFT calculations suggested $\alpha \beta$-deprotonation for $[\mathrm{ATP}-2 \mathrm{H}]^{2-}$ and $\beta$-deprotonation for $[\mathrm{ATP}-\mathrm{H}]^{1-}$.

Gas phase experimental and theoretical studies on a series of mononucleotides compared the dependence of the conformations of these systems on the nature of their nucleobase. ${ }^{35,36}$ It was found that all RNA and DNA mononucleotides adopt the $\mathrm{C}^{\prime}$ endo conformation of the ribose and the anti-conformation of the nucleobase. Exceptions where found for guanosine-5'monophosphate and $2^{\prime}$-deoxyguanosine- $5^{\prime}$-monophosphate in which the nucleobase adapts the syn-conformation.

The widely different biological roles of NTPs suggest that the nucleobase has a non-trivial influence on the structure and recognition of NTPs. The goal of the present study is to characterize the intrinsic properties of deprotonated ATP and how they are affected by the nature of the nucleobase and the degree of deprotonation of the phosphate tail. We present a gas-phase study of ATP and two other NTPs, guanosine $5^{\prime}$-triphosphate (GTP) and cytosine $5^{\prime}$-triphosphate (CTP) (Fig. 1) in two different charge states. Collision-induced dissociation (CID) is performed to evaluate the fragmentation behaviour of the systems, while infrared multiple-photon dissociation (IRMPD) spectroscopy in combination with quantum-chemical calculations is used to map intramolecular hydrogen bond interactions and deprotonation sites. Related systems such as protonated and deprotonated mononucleotides, ${ }^{35-39}$ mononucleotide clusters, ${ }^{40}$ protonated and metal-complexed nucleobases ${ }^{41-48}$ and phosphate-metal complexes $^{49,50}$ have recently been successfully characterized using these methodologies. 


\section{Methods}

\section{Infrared multiple-photon dissociation and collision induced dissociation}

All experiments were performed in a modified commercial quadrupole ion trap mass spectrometer (Bruker, AmaZon Speed ETD). ${ }^{51}$ Ions were generated by electrospray ionization in an Apollo ESI source. Solutions of the NTPs (Sigma-Aldrich, disodium salt hydrates) of $\sim 10^{-6} \mathrm{M}$ (in 50:50 acetonitrile: water, $\sim 2 \% \mathrm{NH}_{4} \mathrm{OH}$ ) were introduced at $120 \mu \mathrm{h} \mathrm{h}^{-1}$ flow rates, electrosprayed and transferred into the trap. The ions of interest were mass-selected and fragmented, either by collisioninduced dissociation (CID) or infrared multiple-photon dissociation (IRMPD).

Tandem mass spectra (MS/MS) of the singly and doubly deprotonated ions were obtained to determine their fragmentation patterns. The ions were activated by $50 \mathrm{~ms}$ of CID with an amplitude parameter of 0.26 . For each ion, twelve mass spectra were recorded and averaged.

IR spectra in the $450-1800 \mathrm{~cm}^{-1}$ region were recorded using the FELIX infrared free electron laser. ${ }^{52}$ FELIX was set to produce IR radiation in the form of 5-10 $\mu \mathrm{s}$ macropulses of 10-80 $\mathrm{mJ}$ at a $10 \mathrm{~Hz}$ repetition rate and with a bandwidth of $\sim 0.4 \%$ of the centre frequency. The mass-selected ions were irradiated with two macropulses in order to average out fluctuations in pulse energy. Spectra were obtained with different levels of attenuation of the laser beam in order to be able to recover weak bands, while avoiding saturation on strong absorptions.

Resonant absorption of IR radiation leads to an increase of the internal energy of an ion mediated by intramolecular vibrational redistribution (IVR), which eventually leads to unimolecular dissociation. ${ }^{28}$ After irradiation, a mass spectrum of the resulting ions in the trap is recorded. At each IR frequency point, 5-6 mass spectra were averaged. The dissociation was calculated from the mass spectra by relating the precursor and fragment ion intensities (yield $=\sum I_{\text {fragmentions }} /\left(I_{\text {parention }}+\right.$ $\left.\sum I_{\text {fragment ions }}\right)$ ). The yield was linearly corrected for frequencydependent laser pulse energy and the frequency was calibrated using a grating spectrometer.

\section{Computational methods}

To obtain optimized molecular geometries and predicted (linear) IR spectra of the singly and doubly deprotonated NTPs, density functional theory (DFT) calculations were performed using Gaussian09. ${ }^{53}$ Input structures for the calculations of the doubly charged anions were defined based on the previously identified $[\mathrm{ATP}-2 \mathrm{H}]^{2-}$ structures calculated by Schinle et al. ${ }^{31}$ A molecular mechanics/molecular dynamics (MM/MD) computational approach using AMBER $12^{54}$ was applied to generate input structures for the mono-anions. Initial guess structures based on the doubly charged anions were first optimized at the B3LYP/6-31++G(d,p) level. After an initial minimization within AMBER, a simulated annealing procedure was used up to $300 \mathrm{~K}$ for the doubly charged anions and up to $500 \mathrm{~K}$ for the monoanions. This temperature range was found to satisfactorily explore the potential energy landscape without dissociation of the molecules. The coordinates of the resulting structures were saved periodically as snapshots throughout the procedure. Five hundred structures were obtained and subsequently clustered based on similarity. The rms atom position criteria were set such that $\sim 50$ candidate structures resulted. Structures for both the mono- and di-anions were further optimized at the B3LYP/6$31++G(d, p)$ level of theory followed by a vibrational frequency calculation within the harmonic approximation. Calculated vibrational spectra were scaled in the $\sim 800-1800 \mathrm{~cm}^{-1}$ region using a linear scaling factor of 0.975 (below $800 \mathrm{~cm}^{-1}$ no scaling factor is applied). Previous studies have shown that phosphate $\mathrm{P}-\mathrm{O}$ and $\mathrm{P}=\mathrm{O}$ stretching frequencies do not require a scaling factor. ${ }^{36,49}$ Therefore, phosphate bands were automatically identified in the output based on the absolute or relative displacements of the phosphate $\mathrm{P}$ and $\mathrm{O}$ atoms in the normal modes, and the corresponding frequencies were left unscaled. The vibrational stick spectra were convoluted with a Gaussian function with $15 \mathrm{~cm}^{-1}$ full width at half maximum to facilitate easy comparison with the experimental spectra. Electronic energies were obtained for the optimized geometries of the singly and doubly charged anions at the B3LYP/6-311+G(d,p), M06-2X/6$311+G(d, p)$ and MP2/6-311++G(2d,2p) levels of theory. These energies were corrected with the thermal free energy values obtained from the B3LYP/6-31++G(d,p) calculations.

\section{Results and discussion}

\section{Fragmentation channels}

ESI-MS signals were observed for the singly and doubly deprotonated ions of ATP, GTP and CTP. The biologically relevant anions with higher charge states were not observed under our experimental conditions. This might be due to a less efficient ESI process for these anions or their inherent instability in the gas phase, which may cause in-source fragmentation. CID MS/ MS spectra of the doubly (left panels) and singly (right panels) charged anions are presented in Fig. 2.

The doubly deprotonated anions $\left([\mathrm{ATP}-2 \mathrm{H}]^{2-},[\mathrm{GTP}-2 \mathrm{H}]^{2-}\right.$ and $[\mathrm{CTP}-2 \mathrm{H}]^{2-}$ ) show mainly a water-free hydrolysis-like fragmentation resulting in phosphate $\left(\mathrm{PO}_{3}{ }^{-}\right)$and deprotonated NDPs $\left([\mathrm{ADP}-\mathrm{H}]^{1-},[\mathrm{GDP}-\mathrm{H}]^{1-}\right.$ and $\left.[\mathrm{CDP}-\mathrm{H}]^{1-}\right)$, which is consistent with previous CID MS/MS data for $[\mathrm{ATP}-2 \mathrm{H}]^{2-30,34}$ This suggests that for doubly deprotonated NTPs in the gas phase, a fragmentation reaction similar to the energy-releasing reaction in living cells is most favourable. In living cells the hydrolysis reaction is water mediated, and therefore the loss of $\left[\mathrm{H}_{2} \mathrm{PO}_{4}\right]^{1-}$ is observed instead of $\left[\mathrm{PO}_{3}\right]^{1-}$. Cercola et al. observed, in addition to these fragments, $\left[\mathrm{HP}_{2} \mathrm{O}_{6}\right]^{1-}$ and deprotonated adenine after activation of $[\mathrm{ATP}-2 \mathrm{H}]^{2-}$, which we do not observe here. ${ }^{34}$ Their harsher MS/MS conditions are likely responsible for this further fragmentation of $[\mathrm{ADP}-\mathrm{H}]^{1-}$.

For singly deprotonated adenine triphosphate, $[\mathrm{ATP}-\mathrm{H}]^{1-}$, mainly three CID fragments are observed. The dominant $\mathrm{m} / \mathrm{z} 408$ fragment is assigned to phosphate loss and subsequent cyclization, yielding cyclic ADP $\left([\mathrm{cADP}-\mathrm{H}]^{1-}\right)$, in line with 

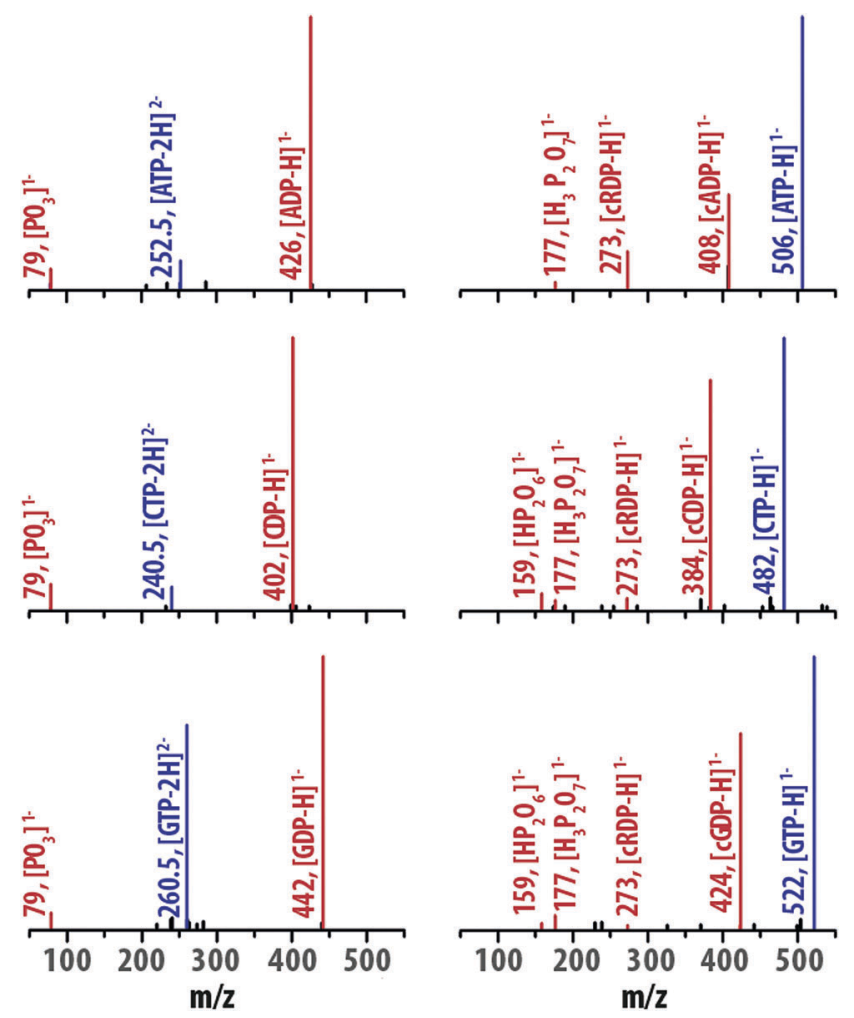

Fig. $2 \mathrm{CID}$ MS/MS spectra of $[\mathrm{ATP}-2 \mathrm{H}]^{2-}$, [GTP-2H] $]^{2-}$ and $[\mathrm{CTP}-2 \mathrm{H}]^{2-}$ (left panels) and $[\mathrm{ADP}-\mathrm{H}]^{1-},[\mathrm{GDP}-\mathrm{H}]^{1-}$ and $[\mathrm{CDP}-\mathrm{H}]^{1-}$ (right panels).

previous CID experiments. ${ }^{30,34}$ The $m / z 273$ peak is assigned to a cyclic ribose diphosphate $\left([\mathrm{cRDP}-\mathrm{H}]^{1-}\right)$, resulting from the same phosphate loss and cyclization, but with additional loss of the nucleobase. The $m / z 177$ peak originates from diphosphate $\left(\mathrm{H}_{3} \mathrm{P}_{2} \mathrm{O}_{7}{ }^{1-}\right)$, resulting from cleavage of the $\alpha \beta$-bond. These major fragmentation channels, and some additional minor fragmentation channels, are also observed for $[\mathrm{GTP}-\mathrm{H}]^{1-}$ and $[\mathrm{CTP}-\mathrm{H}]^{1-}$. Both mono-anions show a clear peak at $\mathrm{m} / \mathrm{z} 159$, which is assigned to the diphosphate anion $\left(\mathrm{HP}_{2} \mathrm{O}_{6}{ }^{1-}\right)$ resulting from water loss and subsequent cyclization of the $\mathrm{H}_{3} \mathrm{P}_{2} \mathrm{O}_{7}{ }^{1-}$ ion. This fragment ion is not observed in the CID MS/MS spectrum of [ATP-H $]^{1-}$ shown in Fig. 2, but it was observed at slightly higher CID energies (not shown). These four fragment ions were also observed by Cercola et $a .^{34}$ in addition to deprotonated ADP, which we do not observe here probably due to our milder CID conditions.

ATP, GTP and CTP show, apart from differences in the relative intensities of the different fragments for the monoanions, an identical fragmentation behaviour. When looking at the relative intensity of the precursor peaks, however, it is observed that $[\mathrm{GTP}-2 \mathrm{H}]^{2-}$ fragments less easily than $[\mathrm{ATP}-2 \mathrm{H}]^{2-}$ and $[\mathrm{CTP}-2 \mathrm{H}]^{2-}$, while $[\mathrm{ATP}-\mathrm{H}]^{1-}$ appears to be slightly more stable than $[\mathrm{GTP}-\mathrm{H}]^{1-}$ and $[\mathrm{CTP}-\mathrm{H}]^{1-}$.

\section{Theoretical results}

Doubly deprotonated NTPs. The theoretical analysis showed that all three NTPs have an extensive conformational space with many local minima. These structures were sorted based on

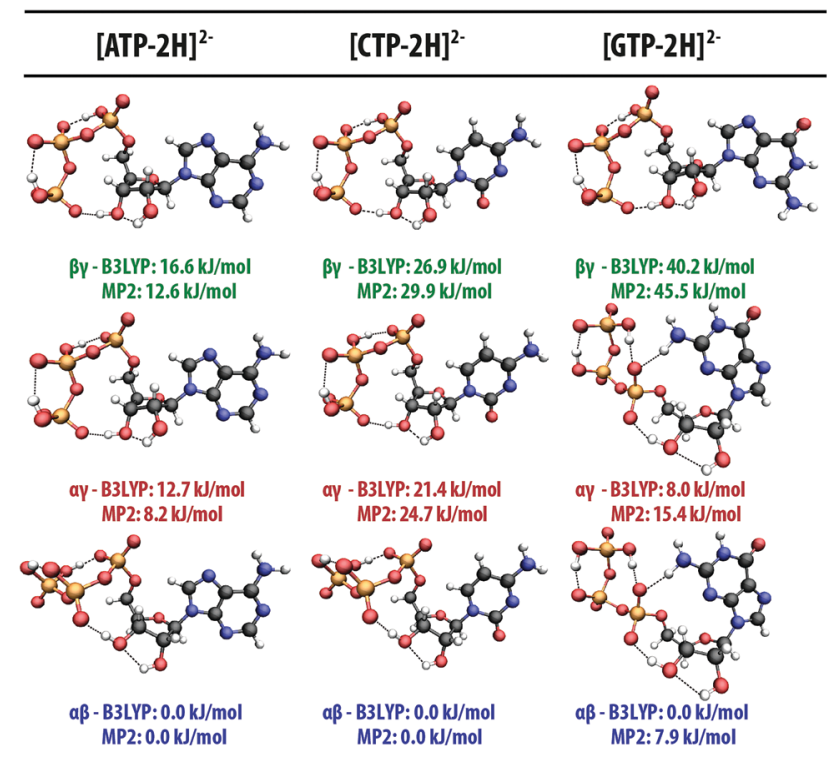

Fig. 3 B3LYP/6-31++G(d,p) optimized structures for the lowest energy conformers of doubly deprotonated ATP, GTP and CTP and their predicted free energies relative to the ground state conformer at the B3LYP/6$31++G(d, p)$ and $M P 2 / 6-311++G(2 d, 2 p)$ levels of theory. The lowest energy conformer (labelled $\alpha \beta 2$ ) of [GTP-H] ${ }^{2-}$ at the MP2/6-311++G(2d,2p) level of theory is presented in Fig. S2 ( $\mathrm{ESI} \dagger)$.

their relative free energy. Fig. 3 presents the lowest-energy conformers found for $\alpha \beta-, \alpha \gamma$ - and $\beta \gamma$-doubly deprotonated ATP, GTP and CTP including their predicted free energies relative to the ground state conformer at the B3LYP/6-31++G(d,p) and MP2/ $6-311++G(2 d, 2 p)$ level of theory. A complete overview of the calculated free energies of these structures on all levels of theory employed is presented in Table T1 in the ESI. $\dagger$ For all NTPs, $\gamma \gamma$-deprotonated structures were found to have significantly higher relative energies and were therefore not considered further. Moreover, none of the low-energy structures resulting from the conformational search were protonated or deprotonated at the nucleobase. For all NTPs the $\alpha \beta$-deprotonated structure is lowest in free energy, followed by $\alpha \gamma$ - and $\beta \gamma$-deprotonation. The three lowest-energy conformers found for $[\mathrm{ATP}-2 \mathrm{H}]^{2-}$ coincide with the lowest energy structures identified by Schinle et $a l^{31}$ and the relative ordering of their energies is also in agreement. The minimum energy structure of $[\mathrm{ATP}-2 \mathrm{H}]^{2-}$ proposed by Burke et $a l^{30}$ was predicted to have a higher free energy than the structure proposed by Schinle et al. (see Fig. S1, ESI $\dagger$ ).

We compare the conformation and hydrogen-bonding patterns of the structures. For all ATP and CTP structures, the nucleobase (adenine or cytidine) prefers the anti-conformation resulting in little interaction with the phosphate tail. Overall, these structures are similar and differ mainly in their hydrogen bonding pattern and the orientation of the phosphate tail, while the conformation of the nucleobase and sugar group remains virtually unchanged. A notable difference for the $\alpha \beta$-conformers is the hydrogen bond between the $\beta$-phosphate and the $3^{\prime}-\mathrm{OH}$ of the ribose group, while in the $\alpha \gamma$ - and $\beta \gamma-$ deprotonated conformers, the $\gamma$-phosphate is involved in this hydrogen bond. This results in a more compact structure for 
the $\alpha \beta$-conformers as compared to the more cyclic folded phosphate tail for the $\alpha \gamma$ - and $\beta \gamma$-deprotonated conformers. The overall low energy predicted for the $\alpha \beta$-conformers suggests that this compact conformation is more favourable. The hydrogenbonding patterns observed in the $\alpha \gamma$ - and $\beta \gamma$-deprotonated conformers is analogous, with as most significant difference the presence of one hydrogen atom on either side of the hydrogen bond between the $\alpha$ - and $\beta$-phosphate.

In contrast, the $\alpha \beta$ - and $\alpha \gamma$-structures of $[\mathrm{GTP}-2 \mathrm{H}]^{2-}$ involve a hydrogen-bond interaction between the $\mathrm{NH}_{2}$-group of the guanine-base and the $\alpha$-phosphate. This hydrogen bond stabilizes a compact conformation with the guanine-base in the synconformation. The hydrogen-bonding pattern in the $\alpha \beta$ - and $\alpha \gamma$-deprotonated GTP structures is similar, with hydrogen bonds between the two $\mathrm{OH}$-groups of the ribose, the $3^{\prime}-\mathrm{OH}$ of the ribose group and the $\alpha$-phosphate and two hydrogen bonds within the phosphate tail. The only difference between the two structures is the location of the hydrogen atom on either side of the hydrogen bond between the $\beta$ - and $\gamma$-phosphate. For $\alpha \beta$-deprotonated GTP, another low-energy structure was found (labelled as the $\alpha \beta$-structure), which is the ground-state conformer on the MP2/6-311++G(2d,2p) level of theory (see Fig. S2, ESI $\dagger$ ). This structure involves a hydrogen bond between the $\mathrm{NH}_{2}$-group of guanine and the $\gamma$-phosphate, but is otherwise similar to the $\alpha \beta$-structure. Although, the doubly deprotonated NTP structures show different interactions depending on the nucleobase, a similar hydrogen bond is formed between the two OH-groups of the ribose.

The $\beta \gamma$-deprotonated GTP structure is analogous to the $\beta \gamma$-structures of CTP and ATP. Moreover, analogous $\alpha \beta$ - and $\alpha \gamma$-deprotonated structures of [GTP-2H] $]^{2-}$ without the nucleobasephosphate tail interactions were found as well. However, the predicted free energies of these conformers are very high compared to the ground-state conformer and therefore they are not further considered here.

For $[\mathrm{CTP}-2 \mathrm{H}]^{2-}$, some of the structures resulting from the conformational search showed nucleobase-phosphate tail interaction. However, presence of these structures can be excluded based on their high relative free energy $\left(>35 \mathrm{~kJ} \mathrm{~mol}^{-1}\right)$. For $[\text { ATP-2H }]^{2-}$, none of the structures showed a nucleobasephosphate tail interaction.

Singly deprotonated NTPs. Fig. 4 presents the low-energy conformers found on the B3LYP/6-31++G(d,p) level of theory for $\beta$-, $\gamma$ - and $\alpha$-deprotonated ATP, GTP and CTP and their predicted relative free energies on the $\mathrm{B} 3 \mathrm{LYP} / 6-31++\mathrm{G}(\mathrm{d}, \mathrm{p})$ and $\mathrm{MP} 2 / 6$ $311++\mathrm{G}(2 \mathrm{~d}, 2 \mathrm{p})$ level of theory. A complete overview of the calculated free energies at all levels of theory employed is presented in Table T2 in the ESI. $\dagger$ For ATP and CTP, the $\beta$-deprotonated structures are lowest in free energy, while the $\alpha$-deprotonated structures are highest in energy. For GTP on the other hand, the $\alpha$-deprotonated structure is lowest in energy, although the energy of the $\beta$-deprotonated structure is comparable. The $\alpha$-deprotonated structure of $[\mathrm{ATP}-\mathrm{H}]^{1-}$ proposed by Burke et al. ${ }^{30}$ (see Fig. S3 in the $\mathrm{ESI} \dagger$ ) was found to have a significantly higher energy and is therefore not included in the current analysis. This difference is perhaps due to the higher level of theory used here.

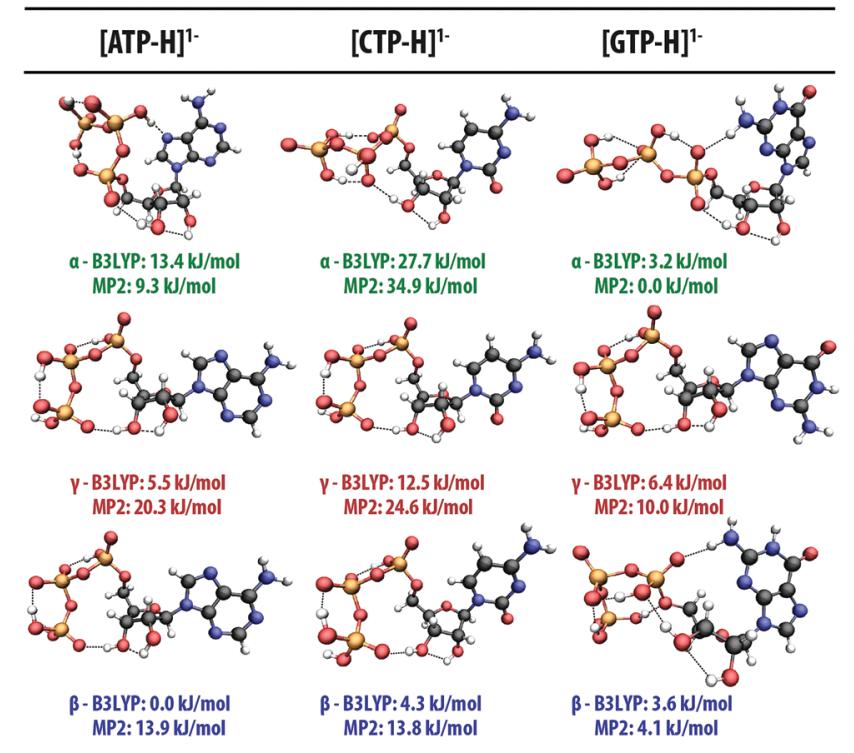

Fig. 4 B3LYP/6-31++G(d,p) optimized structures for the low energy conformers of singly deprotonated ATP, GTP and CTP and their predicted free energies relative to the ground state conformer at the B3LYP/6$31++G(d, p)$ and MP2/6-311++G(2d,2p) levels of theory. The lowest energy conformer of [ATP-H] $]^{1-}$ (labelled $\beta 2$ ) at the MP2/6-311++G(2d,2p) level of theory and the lowest energy conformers of [CTP-H] ${ }^{1-}$ (labelled $\alpha 2, \beta 2$ and $\gamma 2$ ) are presented in Fig. S6 (ESI $\dagger$ ).

Analogous to the doubly deprotonated GTP structures, two of the singly deprotonated GTP-structures (the $\alpha$ - and $\beta$-structures) have a compact conformation with guanine in the syn-conformation and hydrogen-bond interactions between the $\mathrm{NH}_{2}$-group of the nucleobase and the $\alpha$-phosphate group, the two OH-groups of the ribose and the $3^{\prime}-\mathrm{OH}$ of the ribose group and the $\alpha$-phosphate. The two structures not only differ in their deprotonation site, but also show a different hydrogenbonding pattern.

The conformation of the nucleobase and ribose group in all singly deprotonated ATP and CTP species parallels that of their doubly deprotonated conformers, with the base in the anticonformation and a hydrogen bond between the two $\mathrm{OH}$-groups of the ribose. The $\beta$ - and $\gamma$-deprotonated conformers for the two NTPs are similar and show a hydrogen bond between the $\gamma$-phosphate and the $3^{\prime}-\mathrm{OH}$ of the ribose, which results in a cyclic folded conformation of the phosphate tail similar to that of the $\alpha \gamma$ - and $\beta \gamma$-deprotonated structures (Fig. 3). These structures only differ in the presence of one hydrogen-atom on either side of one hydrogen bond.

The $\alpha$-conformer of $[\mathrm{CTP}-\mathrm{H}]^{1-}$ has a hydrogen bond between the $\beta$-phosphate and the $3^{\prime}-\mathrm{OH}$ of the ribose, which results in a compact conformation of the phosphate tail comparable to the one found for the $\alpha \beta$-deprotonated structure (Fig. 3). A comparable $\alpha$-deprotonated structure with a comparable relative free energy was found for $[\mathrm{ATP}-\mathrm{H}]^{1-}$ and is presented in Fig. S3 in the ESI. $\dagger$ This $\alpha$-deprotonated structure coincides with the minimum energy structure of $[\mathrm{ATP}-\mathrm{H}]^{1-}$ proposed by Burke et $a l .{ }^{30}$ However, our calculations suggest that this is not the global minimum. The lowest $\alpha$-deprotonated conformer found 
for $[\text { ATP-H }]^{1-}$ is lower in energy than the other $\alpha$-deprotonated conformers. This conformer is characterized by hydrogen bonds between the $\alpha$-phosphate and the $3^{\prime}-\mathrm{OH}$ of the ribose and one between the $\beta$-phosphate and the N7-atom of adenine. This results in an even more compact folded conformation of the molecule.

The $\gamma$-deprotonated structure of GTP is similar to the $\gamma$-structures of ATP and CTP. Additionally, $\beta$ - and $\alpha$-deprotonated GTP structures (labelled $\alpha 2$ and $\beta 2$ ) were identified that are analogous to the $\beta$ - and $\alpha$-structures of CTP and the $\beta$ - and $\alpha 2$-structures of ATP. The presence of the $\alpha 2$-structure can be excluded based on its high relative free energy (see Fig. S4, ESI $\dagger$ ). The predicted IR spectrum of the $\beta 2$-conformer shows a poorer spectral match with the experiment and is therefore not presented here (see Fig. S5 for details, ESI $\dagger$ ).

For $[\mathrm{CTP}-\mathrm{H}]^{1-}$ an additional set of $\beta$-, $\gamma$ - and $\alpha$-deprotonated structures was found with a lower relative free energy. These structures are characterized by a hydrogen-bond interaction between the $\mathrm{NH}_{2}$-group of the cytosine-base and either the $\beta$ - or $\gamma$-phosphate group. This interaction leads to specific spectral signatures, which causes the predicted IR spectra of these conformers to give a poorer spectral match with the experiment (see Fig. S6, ESI $\dagger$ ).

For $[\mathrm{ATP}-\mathrm{H}]^{1-}$ an additional low-energy $\beta$-deprotonated structure (labelled as $\beta 2$ ) was found with a folded conformation with an interaction between the phosphate tail and the nucleobase. The predicted free energies of this conformer (and also that of the folded $\alpha$-conformer of [ATP-H $]^{1-}$ ) is strongly dependent on the level of theory. The relative energies of these conformers are predicted to be significantly lower at the M06-2X and MP2 levels as compared to the B3LYP predictions. However, the predicted IR spectra of these conformers show a slightly poorer spectral match with the experiment (see Fig. S7, ESI $\dagger$ ).

\section{IRMPD spectroscopic results}

Doubly deprotonated NTPs. Upon IR laser irradiation, all doubly deprotonated NTPs show hydrolysis-like fragmentation as observed in the CID experiments, consistent with previous results for $[\mathrm{ATP}-2 \mathrm{H}]^{2-} \cdot{ }^{31}$ No photo-fragmentation was observed after irradiation at frequencies below $\sim 450 \mathrm{~cm}^{-1}$, which is attributed to inefficient IRMPD at long wavelengths.

The IRMPD spectra in the $450-1800 \mathrm{~cm}^{-1}$ wavelength region were compared to the calculated IR spectra of the low-energy conformers of Fig. 3. Fig. 5 presents the experimental spectrum (black traces) and the calculated spectra (blue, red and green traces) of $[\mathrm{CTP}-2 \mathrm{H}]^{2-}$. The corresponding calculated structures and their relative energies are inlayed in each plot. Although the calculated spectra have several features in common, they differ in detail. Around $1400 \mathrm{~cm}^{-1}$ a feature is observed which is predicted to be a ribose vibration of the $\alpha \beta$-conformers; for the $\alpha \gamma$ - and $\beta \gamma$ conformer this peak is blue shifted due to the different hydrogen bond interaction. In the $1200-1300 \mathrm{~cm}^{-1}$ range, a broad feature is observed that corresponds to the $\mathrm{P}=\mathrm{O}$ stretches in the calculated spectra of all conformers. The shape of the peak matches most favourably with the predicted spectrum of $\alpha \beta$. Between 900 and $1200 \mathrm{~cm}^{-1}$ several bands are observed that are relatively poorly reproduced by the calculations, although the $\alpha \beta$-conformer appears to perform slightly better than the other conformers.

Additionally, the spectrum between 450 and $800 \mathrm{~cm}^{-1}$ is fairly well reproduced by the $\alpha \beta$-conformer. In conclusion,
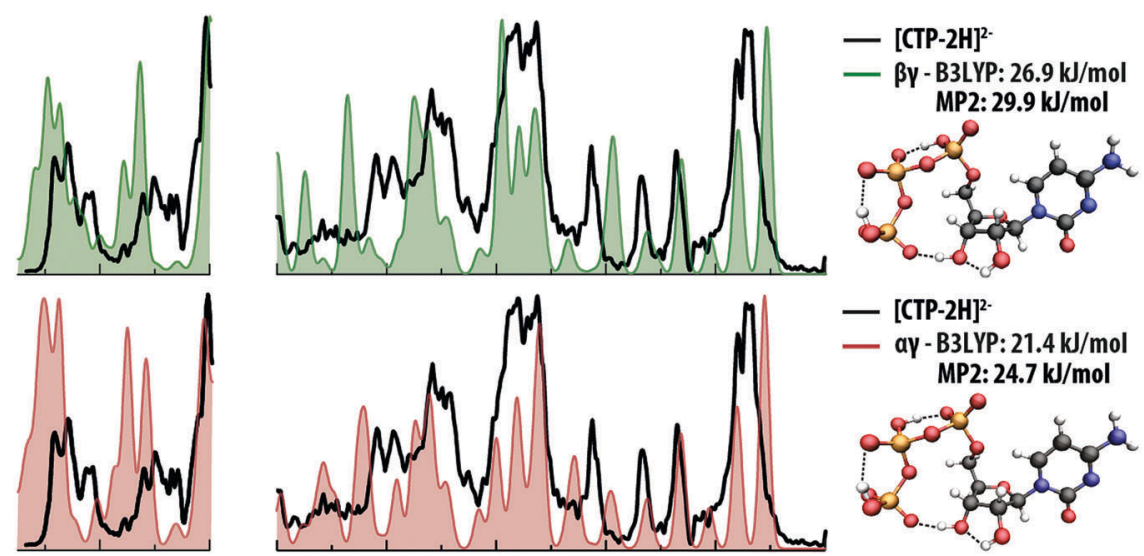

- [CTP-2H $]^{2}$

- aY - B3LYP: $21.4 \mathrm{~kJ} / \mathrm{mol}$ MP2: $24.7 \mathrm{~kJ} / \mathrm{mol}$
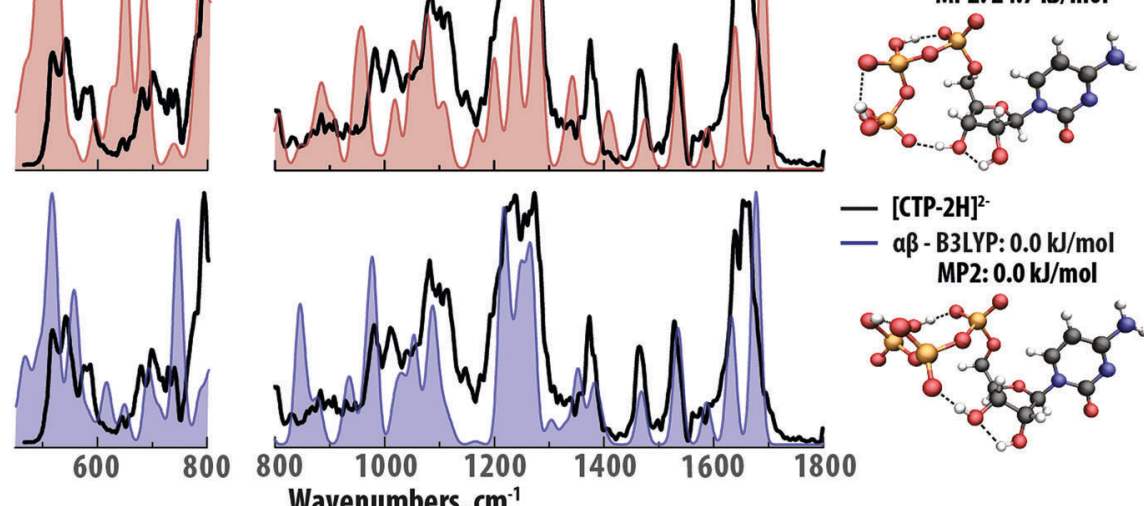

- aß - B3LYP: $0.0 \mathrm{~kJ} / \mathrm{mol}$ MP2: $0.0 \mathrm{~kJ} / \mathrm{mol}$

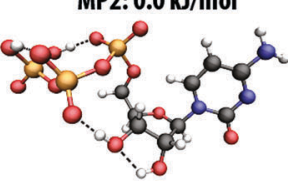

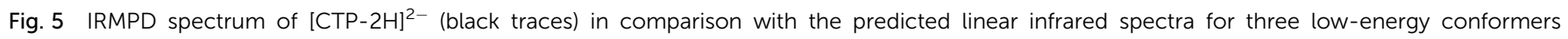

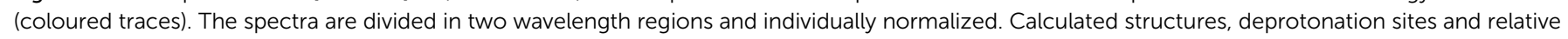
energies are presented next to each panel. 
the $\alpha \beta$-conformer is assigned to have the largest contribution to the ion population in the experiments, which is in agreement with theory.

A similar comparison between recorded and calculated spectra is presented in Fig. S8 (ESI $\dagger$ ) for doubly deprotonated ATP, which results in an analogous assignment of the (groundstate) $\alpha \beta$-conformer. The assigned structure is in agreement with the lowest-energy structures predicted and assigned by Schinle et al. ${ }^{31}$ and Cercola et al. ${ }^{34}$ whereas ref. 30 proposed an $\alpha \beta$-deprotonated conformer with a slightly different hydrogenbonding pattern (see Fig. S1, ESI $\dagger$ ).

Fig. S9 (ESI $\dagger$ ) presents the comparison between the recorded and calculated spectra of $[\mathrm{GTP}-2 \mathrm{H}]^{2-}$. Here, the $\beta \gamma$-structure, which shows no interaction between the $\mathrm{NH}_{2}$ of the nucleobase and the phosphate-tail, can be excluded based on both its high relative free energy (as discussed above) and clear non-matching spectral signatures (see Fig. S2 for details, ESI $\dagger$ ). The number of observed spectral bands in the wavelength region dominated by nucleobase and ribose vibrations (1400-1800 $\mathrm{cm}^{-1}$ ) leads to the conclusion that the experimental spectrum cannot be explained by the predicted IR spectrum of one structure. Based on this, and similar considerations as discussed for the other systems above, a combination of the $\alpha \beta$ - and $\alpha \beta 2$-conformers is assigned to represent the majority of the ion population.

Singly deprotonated NTPs. IR induced dissociation generates fragments identical to those from CID for all singly deprotonated NTPs studied. Analogous to the doubly charged NPTs, no photo-fragmentation is observed upon irradiation at frequencies below $450 \mathrm{~cm}^{-1}$.
In Fig. 6 the IRMPD spectrum of singly deprotonated CTP is compared with calculated spectra for the low-energy conformers displayed in Fig. 4. The line positions of the bands between 1400 and $1800 \mathrm{~cm}^{-1}$, which correspond to vibrations of the nucleobase and ribose-group, are well modelled by the computed spectra for the $\beta$ - and $\alpha$-conformers. In contrast, the shoulder around $1700 \mathrm{~cm}^{-1}$ is slightly redshifted for the $\gamma$-conformer. Moreover, the theoretical spectrum for this conformer predicts intensity around $1400 \mathrm{~cm}^{-1}$, which is not observed experimentally. In the 1150-1400 $\mathrm{cm}^{-1}$ region an intense but only partially resolved feature is observed coinciding with a set of $\mathrm{P}=\mathrm{O}$ stretch vibrations in all conformers. Theory appears to have difficulties to accurately reproduce the experimental feature, especially for the $\alpha$-conformer, which has its strongest absorption just below $1200 \mathrm{~cm}^{-1}$ where the experimental spectrum is nearly silent. Conformers $\beta$ and $\gamma$ predict high intensities at frequencies roughly overlapping with experiment. Three bands are observed between 950 and $1150 \mathrm{~cm}^{-1}$, which are not predicted particularly well for any of the conformers. The band around $1100 \mathrm{~cm}^{-1}$ is perhaps best reproduced by conformer $\alpha$. On the other hand, $\beta$ and $\gamma$ could explain all three bands if the predicted bands are somehow red-shifted; the distance between the three experimental bands is approximately identical to that between the predicted bands. The region between 450 and $800 \mathrm{~cm}^{-1}$ is reproduced better by computed spectra for $\beta$ and $\gamma$ than for $\alpha$, which predicts a particularly strong band in a region of low intensity in the experiment. In conclusion, the $\beta$-conformer is assigned to have the largest contribution to the ion population in the experiments, which is in agreement with the predicted relative free energies.
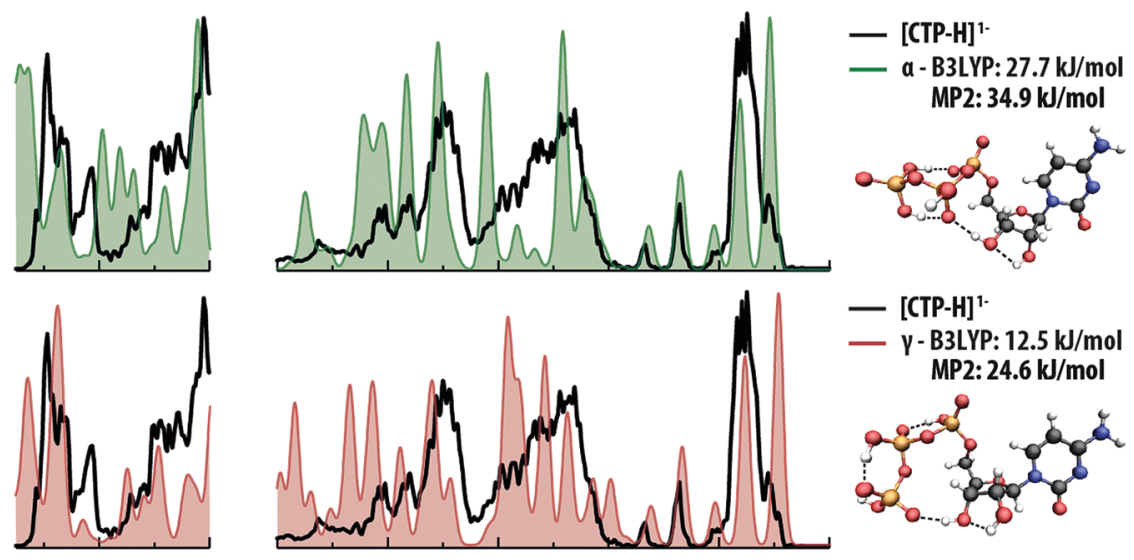

- [CTP-H $]^{1}$

- Y-B3LYP: $12.5 \mathrm{~kJ} / \mathrm{mol}$ MP2: $24.6 \mathrm{~kJ} / \mathrm{mol}$
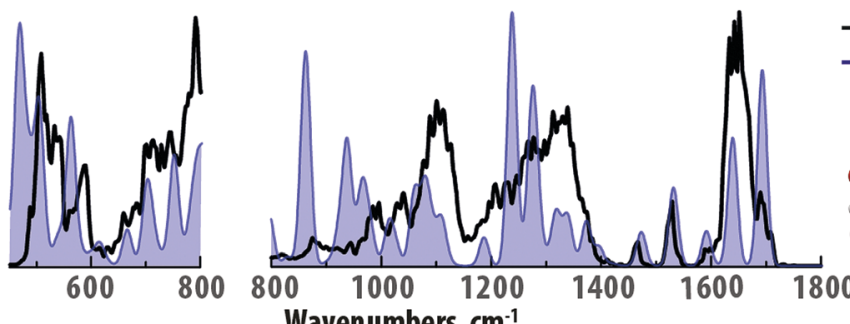

- [CTP-H] ${ }^{1 \cdot}$

- $\beta$ - B3LYP: $4.3 \mathrm{~kJ} / \mathrm{mol}$ MP2: $13.8 \mathrm{~kJ} / \mathrm{mol}$

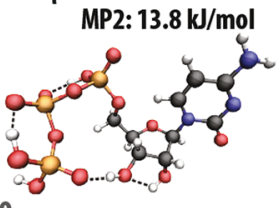

Wavenumbers, $\mathrm{cm}^{-1}$

Fig. 6 IRMPD spectrum of [CTP-H] ${ }^{1-}$ (black traces) in comparison with the predicted linear infrared spectra of three low-energy conformers (coloured traces). The spectra are divided in two wavelength regions that are individually normalized. Calculated structures, deprotonation sites and relative energies are presented next to each panel. 
A similar comparison between the experimental and calculated spectra is performed for singly deprotonated ATP (see Fig. S10 in the ESI $\dagger$ ). Although the differences between the predicted spectra are not as clear as for $[\mathrm{CTP}-\mathrm{H}]^{1-}$, we observe a somewhat better spectral match for the $\beta$-conformer, which is also the lowest-energy conformer at most levels of theory. The $\beta 2$-conformer presented in Fig. S3 (ESI $\dagger$ ) has a lower predicted free energy on the MP2/6-311++G(2d,2p) level of theory and although it shows a slightly poorer spectral match, we cannot exclude it based on the small spectral differences. Therefore, we assign $\beta$-deprotonation based on the predicted relative free energies and the slightly better spectral match. Deprotonation at the $\beta$-phosphate is in agreement with the hypothesis of Cercola et al., ${ }^{34}$ although the hydrogen-bonding pattern assigned here is different.

Fig. S11 $\left(\mathrm{ESI}^{\dagger} \dagger\right)$ presents a comparison of experimental and calculated spectra for $[\mathrm{GTP}-\mathrm{H}]^{1-}$. Here, the $\gamma$-deprotonated structure is, just as the $\beta 2$-structure, excluded based on the poorer spectral match in the $1400-1800 \mathrm{~cm}^{-1}$ wavelength region resulting from the lack of interaction between the $\mathrm{NH}_{2}$-group of the nucleobase and the phosphate tail (see Fig. S5 for details, ESI $\dagger$ ). The IR spectra predicted for the $\beta$ - and $\alpha$-conformers are very similar and their relative free energies are comparable, although the predicted spectrum of the $\beta$-structure shows a slightly better match with the experimental spectrum.
Therefore, we assign the $\beta$-conformer as likely the major contributor to the ion population.

Spectral comparison. Presented in Fig. 7 is a comparison of the experimental spectra of all three $[\mathrm{NTP}-2 \mathrm{H}]^{2-}$ species (black traces) with the predicted spectra for the assigned conformers (blue traces). For [GTP-2H] $]^{2-}$ a second conformer with a significant contribution has been assigned (orange trace). The theoretical analysis correlates experimental features with vibrations of specific parts of the molecule, which enables a meaningful comparison of the experimental spectra of the different NTPs. Both the series of recorded spectra and the series of predicted spectra are significantly different between 1400 and $1800 \mathrm{~cm}^{-1}$. The bands in this region correspond to vibrations of the nucleobase and the ribose moiety. At lower wavenumbers the observed band positions of the different NTPs closely overlap. All spectra contain high intensity bands in the regions between 1150 and $1350 \mathrm{~cm}^{-1}$ and between 950 and $1150 \mathrm{~cm}^{-1}$, which are dominated by symmetric and antisymmetric $\mathrm{P}=\mathrm{O}$ stretches, respectively. The significant similarity between the spectra of the different NTPs in this region can be explained by the fact that all assigned structures have the same deprotonation site. Moreover, despite the different interactions with the nucleobase, the orientation of the phosphate-tail and the hydrogen-bonding pattern between the phosphate-groups is similar for all assigned structures, including the two $[\mathrm{GTP}-2 \mathrm{H}]^{2-}$ structures.

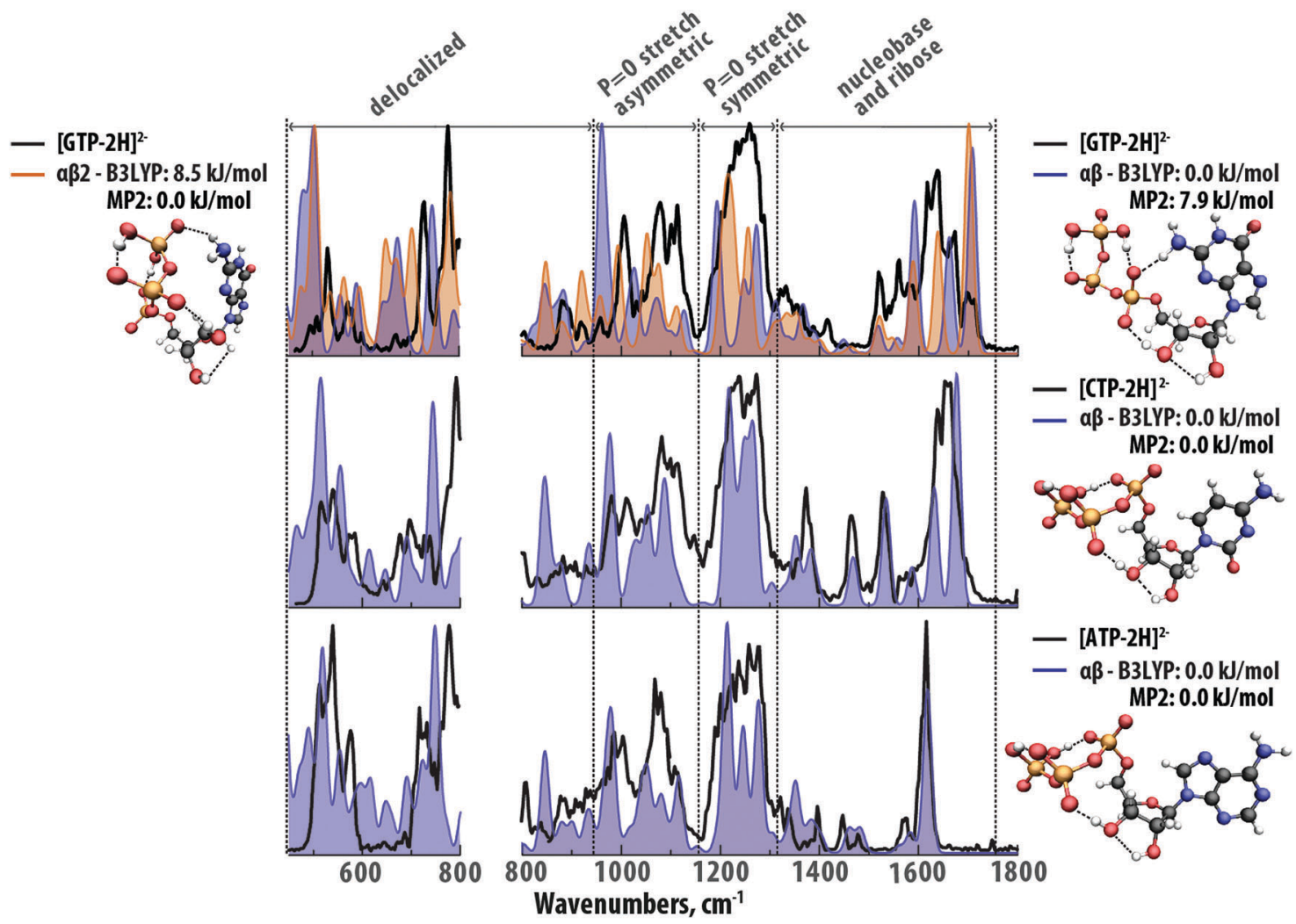

Fig. 7 IRMPD spectra of [ATP-2H] ${ }^{2-}$, [GTP-2H ${ }^{2-}$ and $[\text { CTP-2H }]^{2-}$ (black trace in each panel) in comparison to the predicted linear infrared spectra of the assigned conformers (blue trace in each panel and orange trace in the $[\mathrm{GTP}-2 \mathrm{H}]^{2-}$ panel). The spectra are divided in two wavelength regions and subsequently normalized. Calculated structures, deprotonation sites and relative energies are presented next to each panel. Regions dominated by vibrations of specific parts of the molecules are indicated. 
In the far-infrared region $\left(450-800 \mathrm{~cm}^{-1}\right)$, which is dominated by delocalized vibrational modes, the experimental spectra also show a high degree of similarity. The fact that all assigned structures have the same conformation of the phosphate tail supports the hypothesis of Akola and Jones that this tail is insensitive to the nature of the nucleobase and ribose group. ${ }^{29}$ Moreover, Akola and Jones hypothesized that ATP and GTP might adopt the syn-conformation in the gas phase because of a possible hydrogen bond between the nucleobase and one of the $\mathrm{O}_{\alpha}$-atoms. The assigned GTP structure labelled here as $\alpha \beta$ indeed shows this interaction. For $[\mathrm{ATP}-2 \mathrm{H}]^{2-}$, on the other hand, we assigned a structure with the adenosine-base in the anti-conformation and no interaction of the nucleobase with the phosphate groups.

Fig. 8 presents the IRMPD spectra of $[\text { ATP-H }]^{1-},[\text { GTP-H }]^{1-}$ and $[\mathrm{CTP}-\mathrm{H}]^{1-}$ (black traces) compared with the predicted spectra of the assigned $\beta$-conformers (blue traces). When comparing the spectra in Fig. 7 and 8, one notices that the spectra of the singly deprotonated NTPs contain in general fewer and broader features. This is well reproduced by the calculations. The predicted and experimental spectra of ATP and CTP show parallel features in the regions dominated by $\mathrm{P}=\mathrm{O}$ stretches and by delocalized modes. This supports the conclusion that these NTPs have very similar conformations and only differ in the nature of the nucleobase. GTP shows slightly different features in this region with the absence of well resolved bands around $1000 \mathrm{~cm}^{-1}$ and the presence of a resolved band just below $900 \mathrm{~cm}^{-1}$. This may be related to the fact that the phosphate tail has a different conformation and hydrogen bonding for the assigned structure as compared to the assigned structures of ATP and CTP.

For singly deprotonated ATP and CTP, the modes of the nucleobase and ribose groups observed in the $1400-1800 \mathrm{~cm}^{-1}$ region are very similar to those observed for the corresponding doubly deprotonated NTPs (Fig. 7). This is probably related to the observation that the conformation of the nucleobase and ribose group is relatively unaffected by the charge state for these two NTPs. For GTP, the intensity differences in the experimental spectrum of the singly- versus doubly-deprotonated species in the $1400-1800 \mathrm{~cm}^{-1}$ region can be rationalized by the assignment of a combination of two structures for $[\mathrm{GTP}-2 \mathrm{H}]^{2-}$.

Previous work on singly deprotonated mononucleotides, showed that the anion with the guanosine-base has a synconformation while the other mono-nucleotides adopted the anti-conformation. ${ }^{35,36}$ Here, we observe a similar effect for both the singly and doubly deprotonated NTPs.

Structural comparison. The aim of the present experiments is to define the influence of the nature of the nucleobase and the degree of deprotonation on the properties of NTPs in the gas-phase. Firstly, the CID MS/MS spectra show that at least

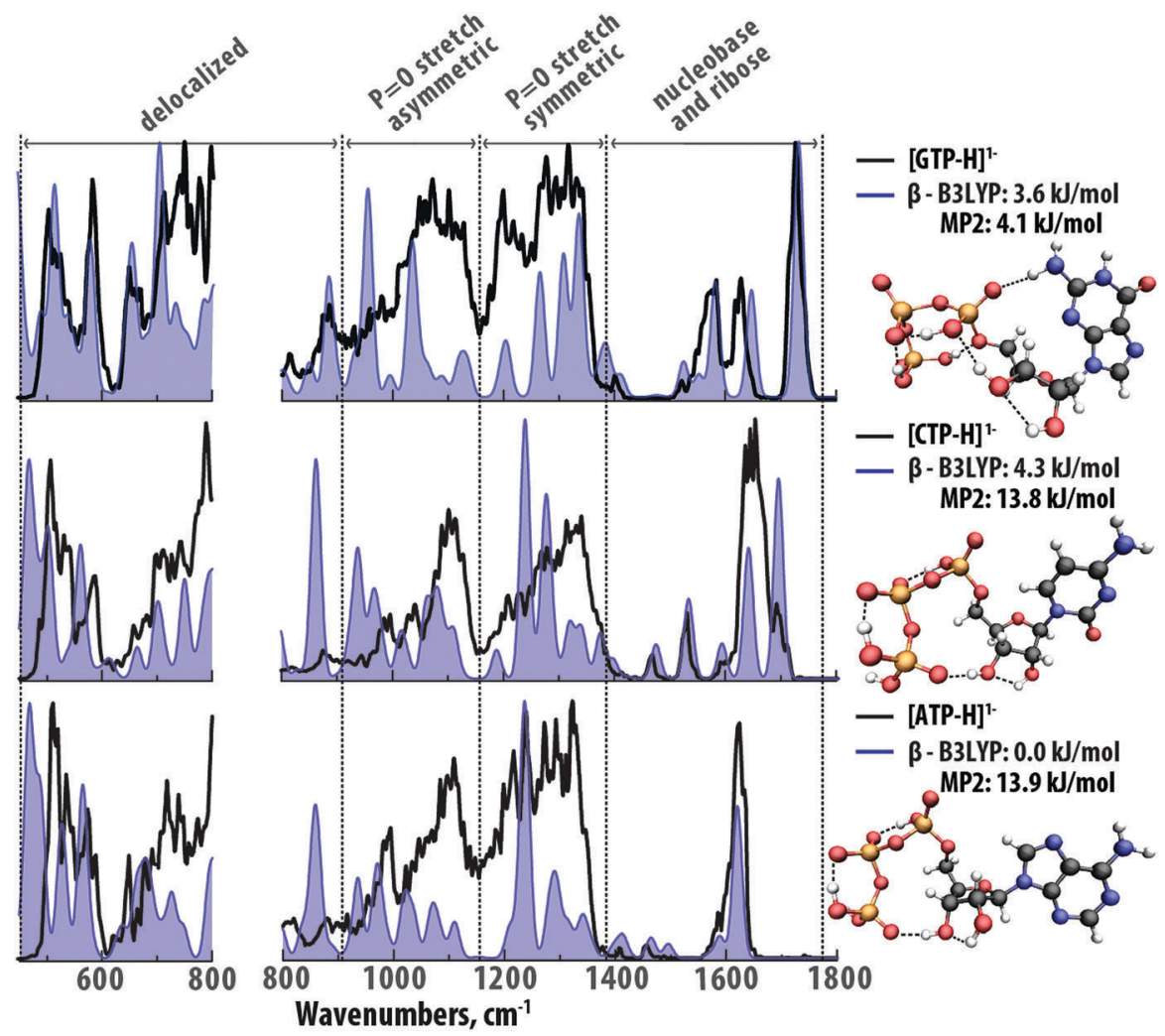

Fig. 8 IRMPD spectra of $[\text { ATP-H }]^{1-},[\text { GTP-H }]^{1-}$ and $[\text { CTP-H }]^{1-}$ (black trace in each panel) in comparison to the predicted linear infrared spectra of the assigned conformers (blue trace in each panel). The spectra are divided in two wavelength regions and subsequently normalized. Calculated structures, deprotonation sites and relative energies are presented next to each panel. Regions dominated by vibrations of specific parts of the molecules are indicated. 
three fragmentation channels are observed for the singly deprotonated NTPs, in contrast to the dominant water-free hydrolysis-like fragmentation for the doubly deprotonated NTPs. This suggests that the extra charge in $[\mathrm{NTP}-2 \mathrm{H}]^{2-}$ aids in making the hydrolysis-reaction more favourable. The three NTPs studied show very similar fragmentation in both singly and doubly deprotonated forms. The nucleobase appears to have little influence on the fragmentation behaviour.

Although it is difficult to exclusively assign one specific conformation based on the IR spectra, we can draw conclusions about the deprotonation sites of the singly and doubly charged anions. All [NTP-2H] $]^{2-}$ species are deprotonated on the $\alpha$ - and $\beta$-phosphate groups, while the $[\mathrm{NTP}-\mathrm{H}]^{1-}$ species are deprotonated at the $\beta$-phosphate group. For ATP and CTP, the conformation of the di-anions is more compact, while the mono-anion structures are more cyclic. This can be attributed to the higher charge requiring a stronger hydrogen bond network involving both the ribose and the phosphate moieties for its stabilization. In contrast, the singly negatively charged systems can be stabilized by a sparser hydrogen-bond network allowing for a less compact, cyclic structure.

Additionally, we observed a difference in the tendency of the studied nucleobases to form a hydrogen-bonding interaction with the phosphate-groups. The results presented here show that guanosine has the largest tendency to form this interaction based on both the theoretical calculations as well as the experimental IR signatures. This tendency is followed by cytosine and adenosine in a decreasing order. Although these structures are experimentally not observed, our calculations show that for $[\mathrm{CTP}-2 \mathrm{H}]^{2-}$ the nucleobase-phosphate tail structures appear as local minima with low energies. For $[\mathrm{ATP}-2 \mathrm{H}]^{2-}$ no nucleobasephosphate tail structures showed up as stable structures in our conformational search. A possible explanation can be found in the structure of the nucleobases (see Fig. 1). That is, when guanosine adapts a syn-conformation, its $\mathrm{NH}_{2}$-group is in very close proximity to the phosphate-groups, favouring a hydrogenbond interaction without much steric hindrance. In contrast, the $\mathrm{NH}_{2}$-group of adenosine and cytosine is located at the 6- and 4-position, respectively, which makes it more unfavourable for the phosphate-tail to bend around to form a hydrogenbonding interaction. On the other hand, the presence of the $\mathrm{C}=\mathrm{O}$ group on the cytosine stabilizes folded structures due to an additional hydrogen-bond possibility between this group and the $2^{\prime}-\mathrm{OH}$ group of the ribose.

In order to put these results in a biochemical context, we compare them with previous studies in the condensed phases. All ATP and CTP ions adopt the anti-conformation, similar to both liquid ${ }^{8,12,23-27}$ and solid phase studies. ${ }^{13-19}$ In condensed media, the phosphate-groups adopt an extended conformation with little interaction between the nucleobase and the $\beta$ - and $\gamma$-phosphate, which is similar to the form in which NTPs are bound to proteins. ${ }^{20,21}$ The backbone conformation of ATP and CTP in the gas-phase is similar to that in biologically relevant environments in the sense that there is no intramolecular interaction between the nucleobase and the phosphate groups. On the other hand, gaseous GTP adopts a syn-conformation with interaction between the phosphate-tail and the base, which is in contrast to the condensed phase studies. Moreover, previous studies have shown that the $[\mathrm{NTP}-2 \mathrm{H}]^{2-}$-and $[\mathrm{NTP}-\mathrm{H}]^{1-}$ species found in the condensed phase under acidic conditions can have a protonated nucleobase, ${ }^{8,25-27}$ while the nucleobases were found to be neutral in our experiments. These differences are in agreement with previous gas-phase studies, ${ }^{29-36}$ and are due to the absence of interactions with water, metal cations or other nucleobases. The favoured deprotonation sites were found to be the $\alpha$ - and $\beta$-phosphate groups, in agreement with studies of the acid-base properties of NTPs in aqueous solutions, which indicate that the $\gamma$-phosphate is less acidic than the $\alpha$ and $\beta$ phosphates. $^{8,25-27}$

\section{Conclusions}

The fragmentation patterns, deprotonation sites and intramolecular hydrogen bond interactions of gas-phase ATP, GTP and CTP were determined using IR ion spectroscopy. ATP and CTP share a common three-dimensional structure where the nucleobase does not interact with the rest of the molecule. For a selected deprotonation state, the NTPs are stabilized by a series of hydrogen bonds between the ribose and phosphate tail. On the other hand, GTP shows a different conformation including interaction of the guanosine-base with the phosphate tail. This difference can be explained by the differences in chemical structure of the nucleobases. Our results show that the charge state of the molecules has a large influence on the hydrogen bond interactions present, the overall three-dimensional structure and the fragmentation pattern. Only the doubly charged anions undergo hydrolysis-like fragmentation.

Future experiments on the structural differences between NTPs will focus on providing further insight in the factors influencing the structures of the biologically relevant species. As NTPs form complexes with one or more metal cations, proteins often recognize the metal complexes of NTPs. Previous IRMPD spectroscopy studies by Rodgers and coworkers have provided a large body of data on metal-complexed nucleobases and nucleosides. ${ }^{41-48}$ IRMPD spectra of metal-complexed NTPs have thus far not been reported and are an important next step in the characterization of the intrinsic interactions of specific NTPs.

\section{Conflicts of interest}

There are no conflicts.

\section{Acknowledgements}

We gratefully acknowledge the Nederlandse Organisatie voor Wetenschappelijk Onderzoek (NWO) for the support of the FELIX Laboratory. Financial support for this project was provided by NWO Chemical Sciences under VICI project nr. 724.011.002. We also thank NWO Physical Sciences and the SurfSARA Supercomputer Centre for providing the computational time and resources (grant 16327). Finally, we wish to 
acknowledge the reviewers of our paper for their attentive and constructive feedback which led us to an improved interpretation of our results.

\section{References}

1 C. Majumdar and F. R. Frankel, Nature, 1973, 243, 33-36.

2 J. P. Abrahams, A. G. W. Leslie, R. Lutter and J. E. Walker, Nature, 1994, 370, 621-628.

3 I. R. Vetter and A. Wittinghofer, Science, 2001, 294, 1299-1304.

4 W. Saenger, Principles of nucleic acid structure, SpringerVerlag, New York, 1984.

5 P. Mitchell, Science, 1979, 206, 1148-1159.

6 P. D. Boyer, Nature, 1999, 402, 247-249.

7 D. L. Nelson and M. M. Cox, Lehninger Principles of Biochemistry, W.H. Freeman and Company, 5th edn, 2008.

8 H. Sigel and R. Griesser, Chem. Soc. Rev., 2005, 34, 875-900.

9 P. Saylor, C. Wang, T. J. Hirai and J. A. Adams, Biochemistry, 1998, 37, 12624-12630.

10 T. Rudack, F. Xia, J. Schlitter, C. Kötting and K. Gerwert, Biophys. J., 2012, 103, 293-302.

11 H. Saint-Martin, L. E. Ruiz-Vicent, A. Ramírez-Solís and I. Ortega-Blake, J. Am. Chem. Soc., 1996, 118, 12167-12173.

12 P. Wang, R. M. Izatt, J. L. Oscarson and S. E. Gillespie, J. Phys. Chem., 1996, 100, 9556-9560.

13 O. Kennard, N. W. Isaacs, J. C. Coppola, A. J. Kirby, S. Warren, W. D. S. Motherwell, D. G. Watson, D. L. Wampler, D. H. Chenery, A. C. Larson, K. A. Kerr and L. R. D. Sanseverino, Nature, 1970, 225, 333-336.

14 R. Cini, M. C. Burla, A. Nunzi, G. P. Polidori and P. F. Zanazzi, J. Chem. Soc., Dalton Trans., 1984, 2467-2476.

15 A. C. Larson, Acta Crystallogr., Sect. B: Struct. Crystallogr. Cryst. Chem., 1978, 34, 3601-3604.

16 P. Orioli, R. Cini, D. Donati and S. Mangani, J. Am. Chem. Soc., 1981, 103, 4446-4452.

17 W. S. Sheldrick, Z. Naturforsch., B: J. Chem. Sci., 1982, 37, 863-871.

18 M. Sabat, R. Cini, T. Haromy and M. Sundaralingam, Biochemistry, 1985, 24, 7827-7833.

19 I. R. Vetter and A. Wittinghofer, Q. Rev. Biophys., 1999, 32, $1-56$.

20 D. Thompson and T. Simonson, J. Biol. Chem., 2006, 281, 23792-23803.

21 P. Satpati, C. Clavaguéra, G. Ohanessian and T. Simonson, J. Phys. Chem. B, 2011, 115, 6749-6763.

22 F. C. Bernstein, T. F. Koetzle, G. J. B. Williams, E. F. Meyer, M. D. Brice, J. R. Rodgers, O. Kennard, T. Shimanouchi and M. Tasumi, Eur. J. Biochem., 1977, 80, 319-324.

23 D. B. Davies, P. Rajani and H. Sadikot, J. Chem. Soc., Perkin Trans. 2, 1985, 279-285.

24 P. O. P. Ts'o, Basic Principles in Nucleic Acid Chemistry, Academic Press, 1974.

25 N. A. Corfù, R. Tribolet and H. Sigel, Eur. J. Biochem., 1990, 191, 721-735.
26 N. A. Corfù and H. Sigel, Eur. J. Biochem., 1991, 199, 659-669.

27 H. Sigel, E. M. Bianchi, N. A. Corfù, Y. Kinjo, R. Tribolet and R. B. Martin, J. Chem. Soc., Perkin Trans. 2, 2001, 507-511.

28 A. M. Rijs and J. Oomens, in Gas-Phase IR Spectroscopy and Structure of Biological Molecules, ed. A. M. Rijs and J. Oomens, Springer International Publishing, Cham, 2015, DOI: 10.1007/128_2014_621, pp. 1-42.

29 J. Akola and R. O. Jones, J. Phys. Chem. B, 2003, 107, 11774-11783.

30 R. M. Burke, J. K. Pearce, W. E. Boxford, A. Bruckmann and C. E. H. Dessent, J. Phys. Chem. A, 2005, 109, 9775-9785.

31 F. Schinle, P. E. Crider, M. Vonderach, P. Weis, O. Hampe and M. M. Kappes, Phys. Chem. Chem. Phys., 2013, 15, 6640-6650.

32 A. A. Arabi and C. F. Matta, J. Phys. Chem. A, 2009, 113, 3360-3368.

33 R. M. Burke and C. E. H. Dessent, J. Phys. Chem. A, 2009, 113, 2683-2692.

34 R. Cercola, E. Matthews and C. E. H. Dessent, J. Phys. Chem. B, 2017, 121, 5553-5561.

35 Y.-w. Nei, K. T. Crampton, G. Berden, J. Oomens and M. T. Rodgers, J. Phys. Chem. A, 2013, 117, 10634-10649.

36 Y.-w. Nei, N. Hallowita, J. D. Steill, J. Oomens and M. T. Rodgers, J. Phys. Chem. A, 2013, 117, 1319-1335.

37 R. R. Wu, C. C. He, L. A. Hamlow, Y. W. Nei, G. Berden, J. Oomens and M. T. Rodgers, J. Phys. Chem. B, 2016, 120, 4616-4624.

38 R. R. Wu, C. C. He, L. A. Hamlow, Y.-w. Nei, G. Berden, J. Oomens and M. T. Rodgers, Phys. Chem. Chem. Phys., 2016, 18, 15081-15090.

39 R. R. Wu, L. A. Hamlow, C. C. He, Y.-w. Nei, G. Berden, J. Oomens and M. T. Rodgers, Phys. Chem. Chem. Phys., 2017, 19, 30351-30361.

40 M. R. Ligare, A. M. Rijs, G. Berden, M. Kabeláč, D. Nachtigallova, J. Oomens and M. S. de Vries, J. Phys. Chem. B, 2015, 119, 7894-7901.

41 R. R. Wu, B. Yang, C. E. Frieler, G. Berden, J. Oomens and M. T. Rodgers, J. Phys. Chem. B, 2015, 119, 5773-5784.

42 R. R. Wu, B. Yang, G. Berden, J. Oomens and M. T. Rodgers, J. Phys. Chem. B, 2015, 119, 2795-2805.

43 R. R. Wu, B. Yang, G. Berden, J. Oomens and M. T. Rodgers, J. Phys. Chem. B, 2014, 118, 14774-14784.

44 R. R. Wu, B. Yang, C. E. Frieler, G. Berden, J. Oomens and M. T. Rodgers, Phys. Chem. Chem. Phys., 2015, 17, 25978-25988.

45 R. R. Wu, B. Yang, C. E. Frieler, G. Berden, J. Oomens and M. T. Rodgers, J. Am. Soc. Mass Spectrom., 2016, 27, 410-421.

46 R. R. Wu, L. A. Hamlow, C. C. He, Y.-w. Nei, G. Berden, J. Oomens and M. T. Rodgers, J. Am. Soc. Mass Spectrom., 2017, 28, 1638-1646.

47 B. O. Yang, R. R. Wu, N. C. Polfer, G. Berden, J. Oomens and M. T. Rodgers, J. Am. Soc. Mass Spectrom., 2013, 24, 1523-1533.

48 Y. Zhu, L. A. Hamlow, C. C. He, J. K. Lee, J. Gao, G. Berden, J. Oomens and M. T. Rodgers, J. Phys. Chem. B, 2017, 121, 4048-4060. 
49 B. S. Fales, N. O. Fujamade, Y.-w. Nei, J. Oomens and M. T. Rodgers, J. Am. Soc. Mass Spectrom., 2011, 22, 81-92.

50 B. S. Fales, N. O. Fujamade, J. Oomens and M. T. Rodgers, J. Am. Soc. Mass Spectrom., 2011, 22, 1862.

51 J. Martens, G. Berden, C. R. Gebhardt and J. Oomens, Rev. Sci. Instrum., 2016, 87, 103108.

52 D. Oepts, A. F. G. Van der Meer and P. W. Van Amersfoort, Infrared Phys. Technol., 1995, 36, 297-308.

53 M. J. Frisch, G. W. Trucks, H. B. Schlegel, G. E. Scuseria, M. A. Robb, J. R. Cheeseman, G. Scalmani, V. Barone, B. Mennucci, G. A. Petersson, H. Nakatsuji, M. Caricato, X. Li, H. P. Hratchian, A. F. Izmaylov, J. Bloino, G. Zheng, J. L. Sonnenberg, M. Hada, M. Ehara, K. Toyota, R. Fukuda, J. Hasegawa, M. Ishida, T. Nakajima, Y. Honda, O. Kitao, H. Nakai, T. Vreven, J. Montgomery, J. A., J. E. Peralta, F. Ogliaro, M. Bearpark, J. J. Heyd, E. Brothers, K. N. Kudin, V. N. Staroverov, R. Kobayashi, J. Normand, K. Raghavachari, A. Rendell, J. C. Burant, S. S. Iyengar, J. Tomasi, M. Cossi,
N. Rega, J. M. Millam, M. Klene, J. E. Knox, J. B. Cross, V. Bakken, C. Adamo, J. Jaramillo, R. Gomperts, R. E. Stratmann, O. Yazyev, A. J. Austin, R. Cammi, C. Pomelli, J. W. Ochterski, R. L. Martin, K. Morokuma, V. G. Zakrzewski, G. A. Voth, P. Salvador, J. J. Dannenberg, S. Dapprich, A. D. Daniels, O. Farkas, J. B. Foresman, J. V. Ortiz, J. Cioslowski and D. J. Fox, Gaussian 09 Revision D.01, Gaussian Inc., Wallingford CT, 2009.

54 D. A. Case, T. A. Darden, T. E. Cheatham III, C. L. Simmerling, J. Wang, R. E. Duke, R. Luo, R. C. Walker, W. Zhang, K. M. Merz, B. Roberts, S. Hayik, A. Roitberg, G. Seabra, J. Swails, A. W. Götz, I. Kolossváry, K. F. Wong, F. Paesani, J. Vanicek, R. M. Wolf, J. Liu, X. Wu, S. R. Brozell, T. Steinbrecher, H. Gohlke, Q. Cai, X. Ye, J. Wang, M.-J. Hsieh, G. Cui, D. R. Roe, D. H. Mathews, M. G. Seetin, R. Salomon-Ferrer, C. Sagui, V. Babin, T. Luchko, S. Gusarov, A. Kovalenko and P. A. Kollman, AMBER 12, University of California, San Francisco, 2012. 